\title{
Chapter 11 \\ Playful Learning Landscapes: \\ Convergence of Education and \\ City Planning
}

\author{
Helen Shwe Hadani, Rebecca Winthrop, and Kathy Hirsh-Pasek
}

\begin{abstract}
Abbreviations
$6 \mathrm{Cs}$ collaboration, communication, content, critical thinking, creative innovation, and confidence

COVID-19 coronavirus disease

PLL Playful Learning Landscapes

SDG Sustainable Development Goal

STEM science, technology, engineering, and math
\end{abstract}

\subsection{Introduction}

When the world's governments committed to the United Nations Sustainable Development Goals (SDGs) in 2015, they agreed not only to address a common set of issues, but to advance a shared agenda of "leaving no one behind." Addressing

\footnotetext{
H. S. Hadani $(\varangle)$

Global Economy and Development and Metropolitan Policy Program, The Brookings Institution, Washington, DC, USA

e-mail: HHadani@brookings.edu

R. Winthrop

Center for Universal Education and Global Economy and Development, The Brookings Institution, Washington, DC, USA

e-mail: RWINTHROP@brookings.edu

K. Hirsh-Pasek

Global Economy and Development, The Brookings Institution, Washington, DC, USA

e-mail: kathy.hirsh-pasek@temple.edu
}

Department of Psychology, Temple University, Philadelphia, USA

S. Ra et al. (eds.), Powering a Learning Society During an Age of Disruption, Education in the Asia-Pacific Region: Issues, Concerns and Prospects 58, https://doi.org/10.1007/978-981-16-0983-1_11 
education inequality is at the heart of SDG 4 and is now more relevant than ever due to school closures from the coronavirus disease (COVID-19). Wealthier families, communities, and countries have found ways to help children continue learning but resource-constrained peers fall farther behind.

In addition to COVID-19, we are also facing complex social challenges that require keeping up with technological innovation, solving problems that require young people to think critically and creatively, identifying and understanding problems we are just encountering, and working together to solve them. Importantly, many of the skills required to be lifelong, engaged learners (e.g., collaboration, communication, content, critical thinking, creative innovation, and confidence-the "6 Cs") are rooted in the science of learning and build on each other beginning at a young age (Golinkoff and Hirsh-Pasek 2016).

The present times are truly a "leapfrog moment" for the global education community. There has never been a more urgent time than now to find new, cost-effective ways of helping young people develop the competencies and skills needed to thrive in work, life, and citizenship. In Leapfrogging Inequality: Remaking Education to Help Young People Thrive (Winthrop et al. 2018), one of the four main pillars for accelerating the pace of change, or "leapfrogging", in education is to harness the learning opportunities of a diversity of in-school and out-of-school experiences. The recent pandemic has thrust the role of out-of-school learning experiences onto the agenda, and there is now more interest than ever to explore innovations that complement school-based learning. One such example is Playful Learning Landscapes (PLL), an approach that can supplement and extend school-based learning, and with a modest cost, provide a needed boost for children who are farthest behind.

\subsection{What Is Playful Learning and Why Is It Important?}

Deep inequalities plague the education systems in many countries. In the United States (US), economic disparities among families lead to large gaps in educational outcomes. Research shows that as early as age three, low-income children lag behind their more affluent peers in language and spatial skills (Golinkoff et al. 2019).

Seeking to close gaps in school readiness and achievement, policy makers have focused on improving access to and quality of formal learning environments. These efforts do not address the $80 \%$ of time that young children spend outside the classroom with their families (Meltzoff et al. 2009). Many children living in underserved communities may have more limited access to enriching learning environments outside of school (e.g., libraries and museums; see Haden 2010), to books in their home, or the kinds of conversations that build cognitive and social capital. This places them at a significant disadvantage relative to their more advantaged peers.

Playful learning is an umbrella term based in science that broadly incorporates how children learn through both free play (voluntary, controlled by the child, and 
nongoal-directed) and guided play (Zosh et al. 2018). In guided play, an adult helps structure activities centered around a learning goal. Importantly, children maintain control over their learning as interactive discoverers. Guided play affords children the opportunity to learn traditional skills like math, literacy, and spatial skills, while promoting creativity, problem solving, and collaboration (Weisberg et al. 2016).

A growing number of studies point to the importance of caregiver-child interactions in language for school readiness and success. More specifically, research demonstrates that kindergarten language scores are the strongest predictor of school achievement across all subjects in third and fifth grade (Pace et al. 2019). With respect to math skills, the amount of spatial language (words such as big, circle, and flat) that parents use with their young children predicts children's spatial thinking, which is an important component of mathematical success (Pruden et al. 2011). Moreover, parents' number talk with their toddlers predicts later understanding of foundational number concepts (Gunderson and Levine 2011).

\subsection{How Children Learn: Playful Learning Principles}

Children learn best when they can be active and engaged in learning that is meaningful, socially interactive, iterative, and joyful (Hirsh-Pasek et al. 2015; Zosh et al. 2018). Six characteristics define playful learning contexts:

(i) Active ("minds on"). Research supports the benefits of active learning — where children are focused and engaged in the learning process through questioning and reflection-over passive learning where students memorize information (Chi 2009). When they are actively involved in the learning process, children can build spatial skills (Bower et al. 2020) and learn properties of shapes (Fisher et al. 2013) and new words (Han et al. 2010).

(ii) Engaging. Filtering out distractions and focusing attention on a task is a central skill. Young children are distracted by inconsequential elements of the environment, as shown by Fisher et al. (2014), who found that kindergarteners who completed science lessons in a highly decorated classroom learned less science content than when they were in a more sparsely decorated classroom.

(iii) Meaningful. When children connect their experiences and interests to new information, their learning is relevant to their own lives. Research in children's museums suggests that adults help children make learning meaningful by highlighting connections between new concepts and personally relevant and familiar information (Callanan et al. 2017).

(iv) Socially interactive. Children frequently play with others and this adds social meaning by constructing new knowledge (Chi 2009). Research finds that cooperative play with peers supports aspects of children's development, including areas of cognitive, social, emotional, and linguistic growth (Berk et al. 2006; Howes et al. 1992). 
(v) Iterative. Children generate, test, and revise hypotheses while interacting with their environment based on data (Gopnik 2012). Learning is an iterative process. Research with preschoolers indicates that children will explore objects and causal relationships more when they observe events that violate their expectations (Schulz and Bonawitz 2007).

(vi) Joyful. Joy and positive emotions are inherent elements of play. Research by Isen et al. (1987) demonstrates that positive affect can boost creativity and make people's thinking more flexible and integrative. A recent model links student participation in activities that bring them joy (e.g., sports and music) to gains in executive function skills and academic outcomes (Diamond 2014).

\subsection{What Children Learn: The 6 Cs-A Breadth of Skills Approach}

Active, engaged, meaningful, socially interactive, iterative, and joyful activities provide a pedagogical framework for how children learn, which leaves open the question of what children need to learn to thrive in the twenty-first century. In today's globalized, rapidly changing world, children need to develop a breadth of skills beyond numeracy and literacy that allow them to engage in independent lifelong learning. The $6 \mathrm{Cs}$-collaboration, communication, content, critical thinking, creative innovation, and confidence-are a suite of skills that are rooted in the science of learning and build on each other (Fig. 11.1).

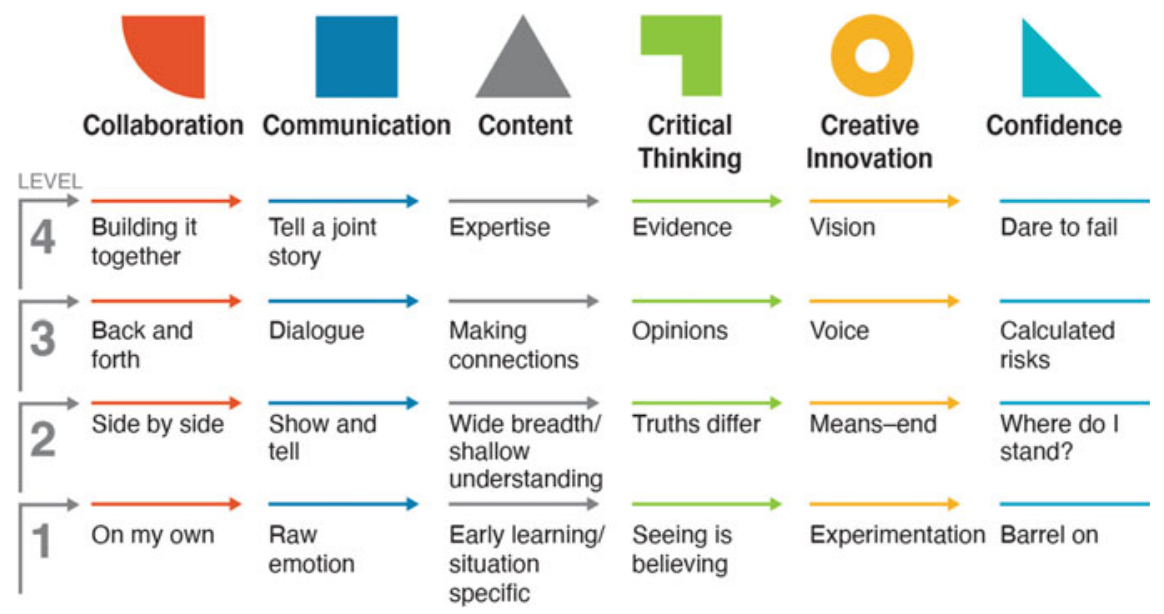

Fig. 11.1 The 6 Cs (The 6 Cs are a suite of skills that offer a breadth of skills approach to developing twenty-first century skills). Source Adapted from Golinkoff, R. M., and Hirsh-Pasek, K. 2016. Becoming brilliant: what science tells us about raising successful children. Washington, DC: American Psychological Association 
The following is a brief description of the $6 \mathrm{Cs}$ as presented by Golinkoff and Hirsh-Pasek (2016) in their book Becoming Brilliant:

(i) Collaboration. Collaboration reflects how social engagement is central to human nature. Interestingly, recent neuroscience research shows how collaborative play yields unique patterns of synchronized brain activity between infants and adults (Piazza et al. 2020).

(ii) Communication. Communication—speaking, writing, reading, and listening - is essential in our daily lives. In early childhood, language skills develop through back-and-forth conversations between children and their parents. Hirsh-Pasek et al. (2015) and many others show that children's kindergarten language skills are the strongest predictor of their academic performance in language, reading, and math, as well as their social skills (for a review, see Pace et al. 2019).

(iii) Content. Traditional content includes reading, writing, math, science, social studies, and the arts, but it is also important to recognize "learning to learn" or executive function skills including attention (Duncan et al. 2007) and working memory (Nguyen and Duncan 2019) that support children's academic achievement. Content builds on collaboration and communication across the disciplines, including math (Bower et al. 2020; Ribner et al. 2020); literacy (Ribner et al. 2020); science; and social studies (Gonzalez et al. 2010).

(iv) Critical thinking. Strong critical thinkers can evaluate the quality of information they receive and ideally use those skills both inside and outside of the classroom (Halpern 2014). The good news is that critical thinking (Halpern 2014) and the related skill of reasoning (Bunge and Leib 2020) can be taught.

(v) Creative innovation. Creative innovation-the synthesis of content and critical thinking — enables students to use what they know to make something new and develop innovative solutions (Kamenetz 2018). Play directly supports that innovation in both language and art (Garaigordobil and Berrueco 2011).

(vi) Confidence. Children who are confident in their abilities demonstrate persistence and flexibility, even when they experience failure. Confidence is closely related to "grit," which is defined as "perseverance and passion for long-term goals" (Duckworth et al. 2007) and "growth mindset," the belief that one can improve their abilities because they are not fixed in time at a particular level (Dweck 2015).

\subsection{Playful Learning Landscapes: A Way to Use the How and What of Learning in Practice}

Together, the how and what of learning offer an evidence-based model of education that can be used in formal and informal learning environments to reduce inequities and encourage leapfrogging.

By merging architectural design and placemaking with the science of learning, PLL embeds learning opportunities in places where families regularly go (e.g., bus 
stops, parks, supermarkets, and laundromats) and transforms them into engaging and enriched learning hubs. The creation of these spaces is guided by the $6 \mathrm{Cs}$ and playful learning principles in what and how children learn. For example, PLL's Urban Thinkscape-which transformed an abandoned lot next to a bus stop in West Philadelphia into an interactive play space-includes a bench with puzzles on the back and a hopscotch game that promotes flexibility and self-control. The activities and structures in Urban Thinkscape provide opportunities for children to engage in high-quality communication with their caregivers and peers, engage in collaborative problem solving, and take risks to build confidence.

While PLL benefits all children, evidence indicates that targeting communities where families have less access to extracurricular enrichment activities (e.g., libraries, museums, summer camps, music lessons) could help them enter and engage in formal schooling on a more level playing field, setting a positive trajectory for life outcomes. When young children enter formal schooling lagging in areas such as language development, spatial skills, and early numeracy, their overall learning trajectories can be set back. These inequities had been growing in many cities prior to the COVID-19 pandemic, which further accelerated the issue (Fisher et al. 2020). Urban public spaces offer a promising yet underutilized platform for dual impact - learning interventions to support learning outcomes in under-resourced communities and activating public spaces for the communal good.

As communities look to "build back better" after COVID-19, there is an opportunity to reimagine the learning environment and supplement the learning that takes place in the classroom by providing enriching, interactive, and social environments in public and shared spaces.

What makes PLL unique is a critical layer of playful learning - a spectrum of child-directed play methods that include free play (no direct adult involvement), guided play (supported by adults toward a learning goal), and games (rule-based activities with learning goals) informed by the latest findings in developmental science (Zosh et al. 2018). As described previously, guided play-the focus of interactions in PLL-allows children to maintain control over their learning with the guidance of an adult to provide structure and focus the activity around a learning goal (e.g., a well-curated exhibit at a children's museum).

Going back to the Urban Thinkscape example, our activities and structures target specific areas of learning including (i) spatial skills, (ii) language development, and (iii) executive function (Hassinger-Das et al. 2020) (Fig. 11.2). The game "jumping feet", a series of stones with either one shoe print or two encourages children to jump following a pattern. Signs prompt children to put one foot where they see two and vice versa. This twist on hopscotch embeds cognitive science in the design of the activity and is based on a task used by researchers to gauge children's memory and attention. The intentionality behind the design is the key component for promoting learning through play. 


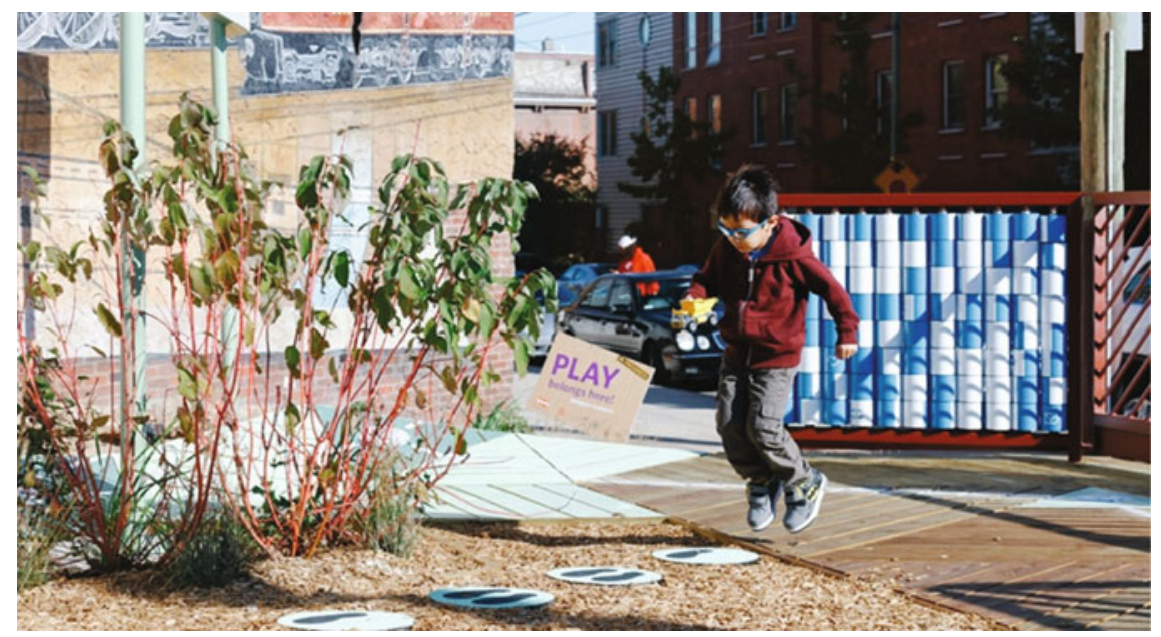

Fig. 11.2 Urban Thinkscape (The game "jumping feet" is a variation of hopscotch that develops children's memory and attention [photo by Sahar Coston-Hardyp]). Source Playful Learning Landscapes Action Network. Urban Thinkscape. https://playfullearninglandscapes.com/project/ urban-thinkscape/. Accessed 5 November 2020

\subsection{Playful Learning Landscapes Work: The Evidence}

Pilots in Chicago, Philadelphia, and Santa Ana in the US have shown that PLL promotes the kinds of caregiver-child behaviors and interactions directly related to later progress in science, technology, engineering, and math (STEM); literacy; and executive function. With more children growing up in socially, economically, and racially stratified neighborhoods, city and community leaders are increasingly looking to PLL as a promising way to engage communities living in low-resourced areas as they design and implement creative spaces where children, caregivers, and community members can interact with one another.

Data from pilot installations and activities demonstrates the following advantages of PLL:

(i) Increases caregivers' attitudes about the connection between play and learning. Parents' understanding of play determines whether and how parents play with their children (Fisher et al. 2008) and what affordances for play children have access to in home and community settings (Chak 2007). The Ultimate Block Party brought over 50,000 people together in New York's Central Park to engage in activities highlighting the link between play and learning. It demonstrated that families are interested in playful learning activities and caregivers' attitudes about the play-learning connection can be shaped in a community setting. Results showed that when parents visited 3-4 playful learning installations, they had more positive attitudes about the 
play-learning connection than did parents who visited fewer installations (Grob et al. 2017).

(ii) Promotes the kinds of caregiver-child communication that supports relationship building and language learning. Research shows that the quantity and quality of language interactions between caregivers and children predict language growth (Adamson et al. 2014; Hart and Risley 1995; Hoff and Naigles 2002). Supermarket Speak transformed a daily trip to the supermarket into a learning opportunity to promote caregiver-child conversations by adding simple signage, "Where does milk come from?" (Fig. 11.3). Results showed a $33 \%$ increase in conversations between children and caregivers when signs were up in under-resourced neighborhoods (Ridge et al. 2015).

In Urban Thinkscape, the bus stop transformation, researchers found a significant increase in conversations between caregivers and children that include six or more turns (where participants speak one at a time in alternating turns). In addition, there was an increase in the number of families using language related to numbers, colors, spatial patterns, and letters (from $2.2 \%$ at pretest to $36 \%$ at posttest) (Hassinger-Das et al. 2020).

(iii) Encourages children's talk about numbers, letters, colors, and spatial relations. Talking about math predicts children's acquisition of number words better than socioeconomic backgrounds (Levine et al. 2010). Parkopolis (Fig. 11.4) enriched a public space with math and science learning by engaging children and their caregivers in a life-size board game where they roll "fraction dice" and move one and a half spaces around the board. Compared to

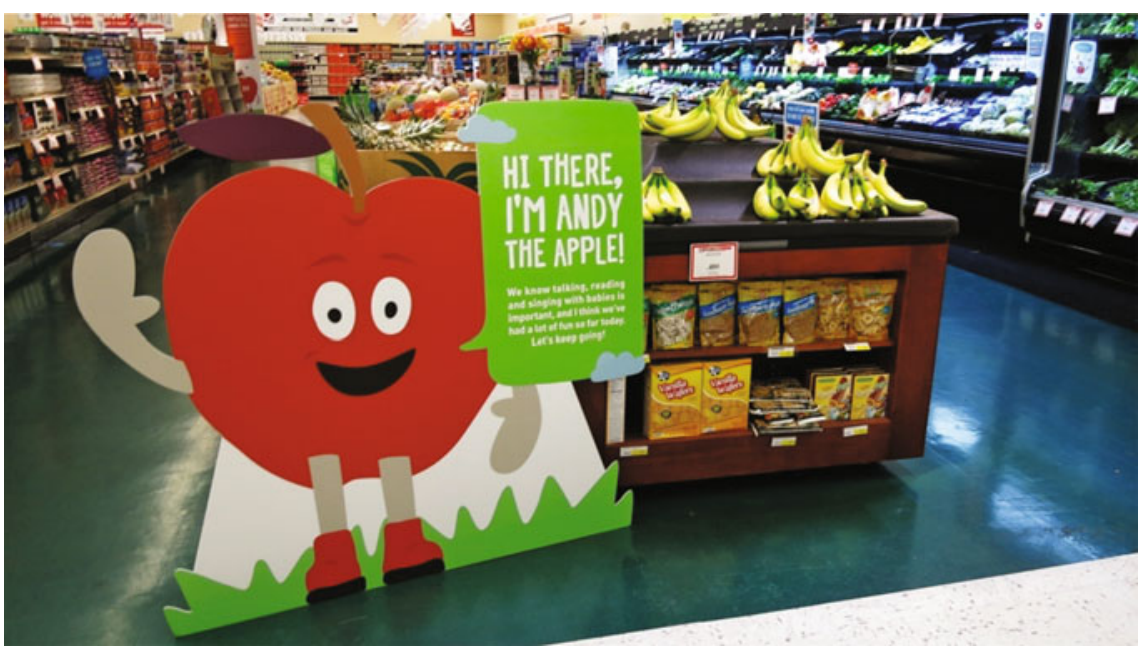

Fig. 11.3 Supermarket Speak (Signage increases conversations between children and caregivers [photo by Sahar Coston-Hardy]). Source Playful Learning Landscapes Action Network. Supermarket Speak. https://playfullearninglandscapes.com/project/supermarket-speak/. Accessed November 2020 


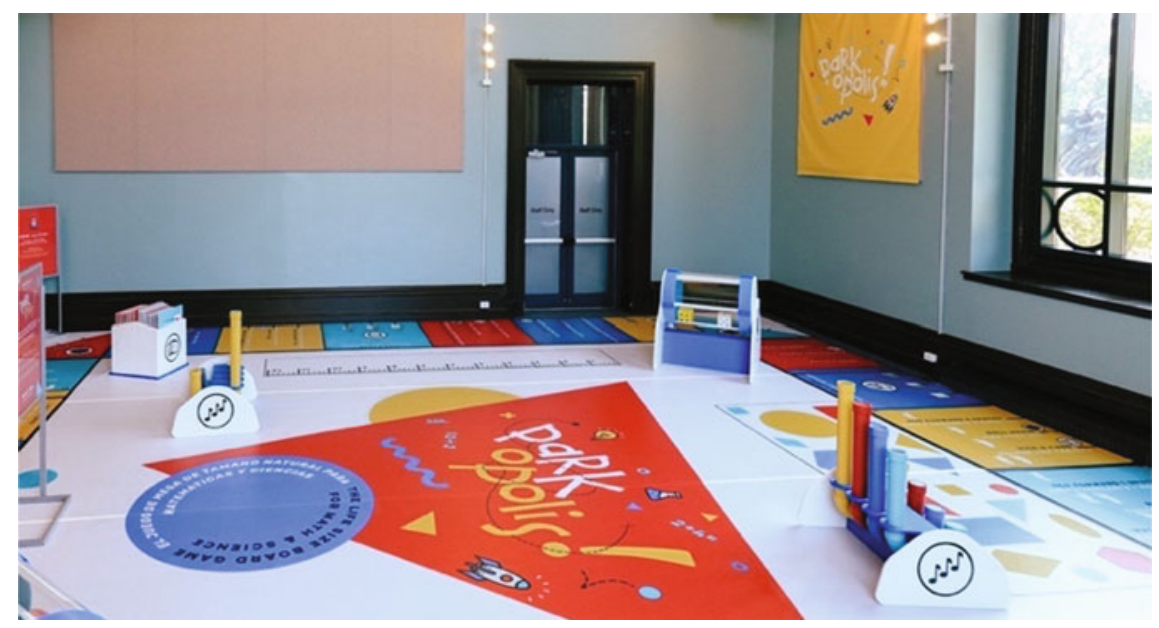

Fig. 11.4 Parkopolis (Parkopolis is a life-size board game where children and their caregivers roll "fraction dice" and move one and a half spaces around the board [photo by Sahar Coston-Hardy]). Source Playful Learning Landscapes Action Network. Parkopolis. https://playfullearninglandsc apes.com/project/parkopolis/. Accessed 5 November 2020

another STEM exhibit, caregivers produced more STEM language, had higher engagement and physical activity, asked more questions, and spent less time on their cell phones in Parkopolis (Bustamante et al. 2020).

Meanwhile, Play and Learn Library embedded playful learning activities in public libraries to promote quality adult-child interactions. Results found that the number of children using spatial-related language — terms referring to size (e.g., big, small); features (e.g., heavy, light); directions (e.g., above, under); or shapes-was $24.2 \%$ higher at the Play and Learn spaces than at the non-Play and Learn sites. Similarly, the number of children using letter- and/or sound-related language (terms referring to colors, letters, or literacy skills) was $18.8 \%$ higher (Hassinger-Das et al. 2020).

(iv) Increases children's understanding of mathematical concepts including fractions and decimal arithmetic. Research shows that rational math (e.g., ratios like fractions and decimals) is a gatekeeper for learning complex math and science concepts (Booth and Newton 2012). PLL's Fraction Ball reimagines the lines of a basketball court to emphasize fractions and decimal learning by allowing children to take shots that are worth a fraction of a point. Results from pilot testing found that students who played fraction ball in physical education class (versus regular physical education classes) demonstrated significantly greater learning from pretest to posttest on assessments of fractions and decimal numbers (Bustamante et al. 2020). 


\subsection{A Path Forward: Scaling Playful Learning in Cities}

A Brookings report on PLL in Philadelphia highlights that the aim of scaling playful learning in cities is moving beyond replication of a single installation to infusing playful learning principles into the mainstream practices of government, businesses, and other organizations (Robinson 2019). Building on that work, Hadani and Vey (2020) discuss five key steps that cities can take to adopt and scale playful learning in their communities.

First, coordination within and across city agencies is needed to support the design and integration of playful learning efforts into new and existing projects. Change at the city level is unlikely without the commitment of the mayor or someone in the mayor's office, but scaling playful learning requires institutionalization and coordination across city agencies - from public works, to transportation, to the health department. For example, in Tel-Aviv, Yafo City and community leaders organized a city-wide event that attracted over 8000 visitors in Rabin Square-a central plaza located in the heart of Tel Aviv-focused on the importance of early childhood and play. Both the theme and location of the event conveyed to the families of Tel Aviv that early childhood and play are a priority for the municipality.

Second, cities do not have to start from scratch. Collaborating with national organizations, many of which are already deeply engaged with local philanthropic, civic, and neighborhood groups to support playful learning, can help to maximize limited resources and increase impact. Internationally, the Playful Learning Landscapes Action Network is working around the world to advise partners on how they can create installations in their cities. In the US, for example, Philadelphia's Playful Learning City initiative, funded by the William Penn Foundation, transformed a bus stop into a learning hub and supermarkets into places that groomed language growth. Too Small to Fail, an initiative of the Clinton Foundation, has created a unique partnership with the Laundry Cares Foundation to transform laundromats into literacy-rich spaces. The national partnership has distributed literacy materials (e.g., children's books and posters featuring parent-child conversation prompts) to 5000 laundromats across the country and helped to facilitate connections with local libraries to deliver programming to families.

Third, working with local partners spurs meaningful engagement with the community, which leads to a better understanding of their needs and ensuring local buy-in. Michigan's Great Start initiative on early childhood reaches local communities by partnering with churches in Detroit to encourage caregivers to talk, read, and sing to their children. Pastors embed messages around early learning and the importance of language-rich experiences for school success in church bulletins, and banners around the church reinforce these messages to families.

Fourth, to reach busy and overwhelmed parents, messaging needs to be concise and shared in various formats and venues. For example, Chicago PlayStreets-a community engagement initiative led by the Chicago Department of Public Health-encourages active play for children and adults by transforming residential streets into safe gathering spaces for families. A key to success of this initiative is 
communicating to residents the important link between physical activity and play for improved cognitive, social, and physical health and development - and how closing streets is a low-cost way to promote exercise and socialization when other play spaces are limited.

Lastly, cities can engage in playful learning through many entry points, but they need to streamline processes to more seamlessly embed playful learning in urban planning and design decisions. One way to address this challenge is training urban planners and designers to embed playful learning into projects and programs from the start so it is not seen as an added effort or cost. Making it easy should not be hard.

\subsection{How Playful Learning Landscapes Allow Us to Build a Breadth of Skills and Leapfrog to Sustainability}

Leapfrogging to promote an effective learning society is only possible if we have the right inputs for children. Young children learn best in active, meaningful, interactive, and engaged contexts. Through fun, interactive installations co-located in spaces that families frequent, PLL encourages the development of critical skills and connections, allowing children from under-resourced neighborhoods to enter into formal schooling on a more even playing field, and setting a positive trajectory for later life outcomes. Through evidence-based engagement and communications strategies, PLL fosters the development of healthy communities by encouraging positive, intergenerational social interaction in public spaces and engaging the community in design and implementation, fostering a sense of pride and responsiveness to community. By thinking differently about the potential of our public and shared spaces, we can enhance urban environments while at the same time making them more powerful experiences for families.

\section{References}

Adamson, L.B., et al. 2014. From interactions to conversations: the development of joint engagement during early childhood. Child Development 85 (3): 941-955.

Berk, L.E., T.D. Mann, and A.T. Ogan. 2006. Make-believe play: Wellspring for development of self-regulation. In Play = learning: How play motivates and enhances children's cognitive and social-emotional growth, ed. D.G. Singer, R.M. Golinkoff, and K. Hirsh-Pasek, 74-100. New York, NY: Oxford University Press.

Booth, J.L., and K.J. Newton. 2012. Fractions: could they really be the gatekeeper's doorman? Contemporary Educational Psychology 37 (4): 247-253.

Bower, C., et al. 2020. Piecing together the role of a spatial assembly intervention in preschoolers' spatial and mathematics learning: Influences of gesture, spatial language, and socioeconomic status. Developmental Psychology 56 (4): 686-698.

Bunge, S.A., and E.R. Leib. 2020. How does education hone reasoning ability? Current Directions in Psychological Science 29 (2): 167-173. 
Bustamante, A., Begoli K., et al. 2020. Having a ball with fractions: fostering math skills through playful learning. https://www.brookings.edu/blog/education-plus-development/2020/07/ 21/having-a-ball-with-fractions-fostering-math-skills-through-playful-learning/. Accessed 13 November 2020.

Bustamante, A.S., M. Schlesinger, et al. 2020. More than just a game: Transforming social interaction and STEM play with Parkopolis. Developmental Psychology 56 (6): 1041-1056.

Callanan, M.A., et al. 2017. Family science talk in museums: Predicting children's engagement from variations in talk and activity. Child Development 88 (5): 1492-1504.

Chak, A. 2007. Teachers' and parents' conceptions of children's curiosity and exploration. International Journal of Early Years Education 15 (2): 141-159.

Chi, M.T.H. 2009. Active-constructive-interactive: a conceptual framework for differentiating learning activities. Topics in Cognitive Science 1 (1): 73-105.

Diamond, A. 2014. Want to optimize executive functions and academic outcomes? Simple, just nourish the human spirit. Minnesota Symposia on Child Psychology 37: 205-232.

Duckworth, A.L., et al. 2007. Grit: Perseverance and passion for long-term goals. Journal of Personality and Social Psychology 92 (6): 1087-1101.

Duncan, G.J., et al. 2007. School readiness and later achievement. Developmental Psychology 43 (6): 1428-1446.

Dweck, C. 2015. Carol Dweck revisits the "growth mindset"-education week. https://www. edweek.org/ew/articles/2015/09/23/carol-dweck-revisits-the-growth-mindset.html. Accessed 13 November 2020.

Fisher, A.V., K.E. Godwin, and H. Seltman. 2014. Visual environment, attention allocation, and learning in young children: When too much of a good thing may be bad. Psychological Science 25 (7): 1362-1370.

Fisher, K.R., et al. 2008. Conceptual split? Parents' and experts' perceptions of play in the 21 st century. Journal of Applied Developmental Psychology 29 (4): 305-316.

Fisher, K.R., et al. 2013. Taking shape: Supporting preschoolers' acquisition of geometric knowledge through guided play. Child Development 84 (6): 1872-1878.

Fisher, P., Lombardi, J., and Kendall-Taylor, N. 2020. Why households with young children warrant our attention and support during (and after) the COVID-19 pandemic. https://medium. com/rapid-ec-project/why-households-with-young-children-warrant-our-attention-and-supportduring-and-after-the-b7cee9b76184. Accessed 13 November 2020.

Garaigordobil, M., and L. Berrueco. 2011. Effects of a play program on creative thinking of preschool children. The Spanish Journal of Psychology 14 (2): 608-618.

Golinkoff, R.M., and K. Hirsh-Pasek. 2016. Becoming brilliant: What science tells us about raising successful children. Washington, DC: American Psychological Association.

Golinkoff, R.M., et al. 2019. Language matters: Denying the existence of the 30-million-word gap has serious consequences. Child Development 90 (3): 985-992.

Gonzalez, J.E., et al. 2010. Developing low-income preschoolers' social studies and science vocabulary knowledge through content-focused shared book reading. Journal of Research on Educational Effectiveness 4 (1): 25-52.

Gopnik, A. 2012. Scientific thinking in young children: theoretical advances, empirical research, and policy implications. Science 337 (6102): 1623-1627.

Grob, R., et al. 2017. Playing with ideas: evaluating the impact of the Ultimate Block Party, a collective experiential intervention to enrich perceptions of play. Child Development 88 (5): $1419-1434$.

Gunderson, E.A., and S.C. Levine. 2011. Some types of parent number talk count more than others: relations between parents' input and children's cardinal-number knowledge. Developmental Science 14 (5): 1021-1032.

Hadani, H.S., and Vey, J.S. 2020. Scaling playful learning: how cities can reimagine public spaces to support children and families. https://www.brookings.edu/research/scaling-playful-lea rning-how-cities-can-reimagine-public-spaces-to-support-children-and-families/. Accessed 13 November 2020. 
Haden, C.A. 2010. Talking about science in museums. Child Development Perspectives 4 (1): 62-67.

Halpern, D.F. 2014. Thought and knowledge: An introduction to critical thinking. New York: Psychology Press.

Han, M., et al. 2010. Does play make a difference? How play intervention affects the vocabulary learning of at-risk preschoolers. The American Journal of Play 3 (1): 82-105.

Hart, B., and T.R. Risley. 1995. Meaningful differences in the everyday experience of young American children. Baltimore: Paul H. Brookes.

Hassinger-Das, B., I. Palti, et al. 2020a. Urban Thinkscape: Infusing public spaces with STEM conversation and interaction opportunities. Journal of Cognition and Development 21 (1): $125-147$.

Hassinger-Das, B., J.M. Zosh, et al. 2020b. Play-and-learn spaces: leveraging library spaces to promote caregiver and child interaction. Library and Information Science Research 42 (1): 101002.

Hirsh-Pasek, K. 2020. A new path to education reform: playful learning promotes 21 st century skills in school and beyond. Policy Brief. Brookings Institution. https://www.brookings.edu/pol icy2020/bigideas/a-new-path-to-education-reform-playful-learning-promotes-21st-century-ski 1ls-in-schools-and-beyond/. Accessed 13 November 2020.

Hirsh-Pasek, K., L.B. Adamson, et al. 2015a. The contribution of early communication quality to low-income children's language success. Psychological Science 26 (7): 1071-1083.

Hirsh-Pasek, K., J.M. Zosh, et al. 2015b. Putting education in "educational" apps: Lessons from the science of learning. Psychological Science in the Public Interest 16 (1): 3-34.

Hoff, E., and L. Naigles. 2002. How children use input to acquire a lexicon. Child Development 73 (2): 418-433.

Howes, C., O. Unger, and C.C. Matheson. 1992. The collaborative construction of pretend: Social present play functions. Albany: State University of New York Press.

Isen, A.M., K.A. Daubman, and G.P. Nowicki. 1987. Positive affect facilitates creative problem solving. Journal of Personality and Social Psychology 52 (6): 1122-1131.

Kamenetz, A. 2018. Raising brilliant kids—With research to back you up. https://www.npr.org/sec tions/ed/2018/07/23/627265706/raising-brilliant-kids-with-research-to-back-you-up. Accessed 13 November 2020.

Levine, S.C., et al. 2010. What counts in the development of young children's number knowledge? Developmental Psychology 46 (5): 1309-1319.

Meltzoff, A.N., et al. 2009. Foundations for a new science of learning. Science 325 (5938): 284-288.

Nguyen, T., and G.J. Duncan. 2019. Kindergarten components of executive function and third grade achievement: A national study. Early Childhood Research Quarterly 46: 49-61.

Pace, A., et al. 2019. Measuring success: Within and cross-domain predictors of academic and social trajectories in elementary school. Early Childhood Research Quarterly 46: 112-125.

Piazza, E.A., et al. 2020. Infant and adult brains are coupled to the dynamics of natural communication. Psychological Science 31 (1): 6-17.

Pruden, S.M., S.C. Levine, and J. Huttenlocher. 2011. Children's spatial thinking: Does talk about the spatial world matter? Children's spatial thinking. Developmental Science 14 (6): 1417-1430.

Ribner, A.D., C.S. Tamis-LeMonda, and L.S. Liben. 2020. Mothers' distancing language relates to young children's math and literacy skills. Journal of Experimental Child Psychology 196: 104863.

Ridge, K.E., et al. 2015. Supermarket Speak: Increasing talk among low-socioeconomic status families. Mind, Brain, and Education 9 (3): 127-135.

Robinson, J.P. 2019. Philadelphia playful learning landscapes. https://www.brookings.edu/research/ philadelphia-playful-learning-landscapes/. Accessed 13 November 2020.

Schulz, L.E., and E.B. Bonawitz. 2007. Serious fun: Preschoolers engage in more exploratory play when evidence is confounded. Developmental Psychology 43 (4): 1045-1050.

Weisberg, D.S., et al. 2016. Guided play: Principles and practices. Current Directions in Psychological Science 25 (3): 177-182. 
Winthrop, R., A. Barton, and E. McGivney. 2018. Leapfrogging inequality: Remaking education to help young people thrive. Washington, DC: Brookings Institution Press.

Zosh, J.M., et al. 2018. Accessing the inaccessible: redefining play as a spectrum. Frontiers in Psychology 9: 1124.

The opinions expressed in this chapter are those of the author(s) and do not necessarily reflect the views of the Asian Development Bank, its Board of Directors, or the countries they represent.

Open Access This chapter is licensed under the terms of the Creative Commons Attribution-NonCommercial 3.0 IGO license (http://creativecommons.org/licenses/by-nc/3.0/igo/) which permits any noncommercial use, sharing, adaptation, distribution and reproduction in any medium or format, as long as you give appropriate credit to the Asian Development Bank, provide a link to the Creative Commons license and indicate if changes were made.

Any dispute related to the use of the works of the Asian Development Bank that cannot be settled amicably shall be submitted to arbitration pursuant to the UNCITRAL rules. The use of the Asian Development Bank's name for any purpose other than for attribution, and the use of the Asian Development Bank's logo, shall be subject to a separate written license agreement between the Asian Development Bank and the user and is not authorized as part of this CC-IGO license. Note that the link provided above includes additional terms and conditions of the license.

The images or other third party material in this chapter are included in the chapter's Creative Commons license, unless indicated otherwise in a credit line to the material. If material is not included in the chapter's Creative Commons license and your intended use is not permitted by statutory regulation or exceeds the permitted use, you will need to obtain permission directly from the copyright holder.

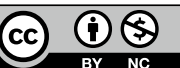

